Cite as: Eiroa-Orosa, F. J., Haasen, C., Verthein, U., Dilg, C., Schäfer, I., \& Reimer, J. (2010). Benzodiazepine use among patients in heroin-assisted vs. methadone maintenance treatment: Findings of the German randomized controlled trial. Drug and Alcohol Dependence, 112(3), 226-233.

https://doi.org/10.1016/j.drugalcdep.2010.06.013

Benzodiazepine use among patients in heroin-assisted vs. methadone maintenance treatment: findings of the German randomized controlled trial

Eiroa-Orosa, F.J., Haasen, C., Verthein, U., Dilg, C., Schäfer, I., Reimer, J.

Francisco José Eiroá Orosa. feiroa@gmail.com. Centre for Interdisciplinary Addiction Research, University Medical Centre Eppendorf Hamburg, Martinistr. 52. 20246 Hamburg. Germany. - Psychiatry Department, University Medical Center Vall d'Hebron, Passeig Vall d'Hebron, 119-129 08035 Barcelona, Spain.

Corresponding author: Prof. Dr. Christian Haasen. haasen@uke.uni-hamburg.de. Centre for Interdisciplinary Addiction Research, University Medical Centre Eppendorf Hamburg, Martinistr. 52. 20246 Hamburg. Germany. Tel. 040 / 42803-7901. Fax 040 / 42803-8351.

Dr. Uwe Verthein. verthein@sozialwiss.uni-hamburg.de. Centre for Interdisciplinary Addiction Research, University Medical Centre Eppendorf Hamburg, Martinistr. 52. 20246 Hamburg. Germany.

Dr. Christoph Dilg. christoph.dilg@ukb.uni-bonn.de. Department of Psychiatry, University Hospital, Bonn. Germany.

Dr. Ingo Schäfer. i.schaefer@uke.uni-hamburg.de. Center for Interdisciplinary Addiction Research, University Medical Centre Eppendorf Hamburg, Martinistr. 52. 20246 Hamburg. Germany.

Dr. Jens Reimer. reimer@uke.uni-hamburg.de. Center for Interdisciplinary Addiction Research, University Medical Centre Eppendorf Hamburg, Martinistr. 52. 20246 Hamburg. Germany. 


\title{
Benzodiazepine use among patients in heroin-assisted vs. methadone maintenance treatment: findings of the German randomized controlled trial
}

\begin{abstract}
Benzodiazepine (BZD) use has been found to be associated with poorer psychosocial adjustment, higher levels of polydrug use and more risk-taking behaviors among opioid dependent patients. The aim of this paper is to analyze the correlation between BZD use, BZD prescription and treatment outcome among participants in the German trial on heroin assisted treatment. 1015 patients who participated in the study comparing heroin assisted and methadone maintenance treatment (HAT \& MMT) for 12 months were included in the analysis. Analyses were carried out to assess the association of treatment outcome with baseline BZD use, with ongoing BZD use and with different patterns of BZD prescription. Baseline BZD use correlated with lower retention rates but not with poorer outcome. Ongoing BZD use correlated with poorer outcomes. Significantly better outcomes were found in the course of phobic anxiety symptomatology for those with regular prescription of BZD. The percentage of BZD positive urine tests decreased more in HAT than in MMT. Poorer outcome for benzodiazepine users may be mediated by a higher severity of addiction. Cautious prescribing of benzodiazepines may be beneficial due to the reduction of overall illicit use.
\end{abstract}

Keywords: Benzodiazepines, prescriptions, diamorphine, heroin-assisted treatment, methadone maintenance, opioid dependence 


\section{Introduction}

The association between benzodiazepine use and abuse and a more complicated, negative clinical course of heroin dependence has been well established. Previous research shows that injecting drug users (IDUs) using benzodiazepines (BZDs) are more likely to show risk behaviors such as sharing injecting equipment, therefore having a higher rate of hepatitis $\mathrm{C}$ and polydrug use, and to have more psychosocial problems and higher levels of psychopathology (Darke, 1994). When entering methadone maintenance treatment (MMT), clients using benzodiazepines are more likely to have a higher severity of addiction, more polydrug use and risk behavior, greater number of previous nonfatal overdoses, and more mental health and social problems (Bleich et al., 1999; Brands et al., 2008; Darke et al., 1993; Meiler et al., 2005).

Regarding possible interventions for BZD abuse during treatment, Stitzer et al. (1982) reported successful use of contingent reinforcement of drug-free urines to minimize the use of benzodiazepines among MMT users. An Australian study (Weizman et al., 2003) compared two therapeutic modalities for BZD dependent patients in MMT: either BZD detoxification or BZD maintenance showing that those maintained on BZD are more successful than those detoxified from BZD. In this study, psychiatric comorbidity was positively related to success of BZD maintenance treatment. Meiler et al. (2005) analyzed the prescription and use of benzodiazepines in a sample of MMT clients and found a high proportion of patients who reported medically prescribed BZD use $(92.3 \%)$. These authors pointed out that physicians find themselves in a dilemma: Not prescribing means a high risk of dropout while prescribing can risk maintaining BZD dependency. Bramness and Kornør (2007) analyzed BZD prescription in methadone and buprenorphine programs in Norway and found a $40 \%$ overall prescription rate and a mean dose of $36 \pm 69 \mathrm{mg}$ Diazepam equivalents. Although it 
corresponded with the estimated prevalence of anxiety disorders for clients in maintenance treatment, the authors outlined the possible negative effects of such a high dose practice.

An official document of the U.S. Department of Health and Human Services states that "the use of benzodiazepines in medication-assisted treatments for opioid addiction, when used in prescribed doses, are not dangerous for patients, except when they cause patients to seek other drugs with sedative effects" (Batki et al., 2005). Previously, benzodiazepine prescription to addicted patients was discouraged despite evidence suggesting it is "helpful to a certain population of patients with addictions" (Johnson and Longo, 1998). Seivewright and Iqbal (2002) suggest that there is a fine line between misuse and therapeutic use of BZDs among drug dependent patients and that prescribing may be helpful but should be done with extreme caution. Nevertheless there are no controlled studies offering evidence of benefits or disadvantages of BZD prescription in maintenance treatment.

One study analyzed the impact of benzodiazepine prescription and abuse among patients with dual disorders (drug dependence and another mental disorder) in a community health system (Brunette et al., 2003). The authors found that the use of prescribed benzodiazepines was not related to negative substance abuse outcomes, but these patients were more likely to develop benzodiazepine abuse. Furthermore, they reported no improvement of depressive or anxious symptoms in patients treated with BZD and recommend the use of other treatments.

The evidence therefore implies that BZD users in MMT can be among the most difficult to treat patients. Recently, it has been suggested that more difficult-to-treat patients may do better in maintenance treatment using diamorphine (heroin). Clinical studies in Switzerland (Perneger et al., 1998; Rehm et al., 2001), the Netherlands (Blanken et al., 2005; van den Brink et al., 2003), Spain (March et al., 2006), Germany (Haasen et al., 2007; Verthein et al., 2008) and Canada (Oviedo-Joekes et al., 2009) have found heroin-assisted 
treatment (HAT) to be more effective than MMT in the treatment of methadone nonresponders. However, these studies have not analyzed the effect of HAT compared to MMT on BZD use. Furthermore, no studies have been published comparing the outcome of maintenance treatment in patients with or without additional prescribed BZD. The objective of the present study is to evaluate the prevalence and correlates of BZD use at baseline and during treatment as well as patterns of BZD prescription for patients in the German heroin trial comparing HAT and MMT in opioid dependent patients.

\section{Materials and methods}

\section{The German trial on heroin assisted treatment of opioid dependent patients}

HAT and MMT were compared in a multicenter trial among 1015 patients in 7 cities in Germany. This sample resulted from screening 2038 heroin dependent patients. Patients meeting inclusion and exclusion criteria were randomised into four subgroups depending on type of medication (heroin or methadone) and psychosocial care received (psychoeducation plus individual counselling or case management plus motivational interviewing). Participants were recruited from two target groups: those insufficiently responding to other maintenance treatments and those dependent on heroin but not in treatment in the previous 6 months. Treatment duration was 12 months. HAT patients received a maximum of three doses of intravenous diamorphine (heroin) per day (average dose: $442 \mathrm{mg} / \mathrm{d}$, maximum dose: 1000 $\mathrm{mg} / \mathrm{d}$ ) with an additional (maximum of) $60 \mathrm{mg}$ oral methadone take-home when needed, while MMT patients received one single daily dose of oral methadone individually adjusted according to clinical judgement (average dose: 99mg/d). Additional prescription of psychopharmacological drugs, including benzodiazepines, was decided for each patient individually based upon the respective psychopathology, and there was no restriction on the prescription of benzodiazepines. Primary health care was covered by the trial team, referrals to other specialists and hospitals occurred for specific treatments. However, as medical 
coverage in Germany allows patients to consult any doctor, benzodiazepine prescription could occur outside the trial coverage, but this was unlikely since there were no restrictions on prescriptions of these medications in the frame of the study. Therefore, the use of BZD not prescribed in the trial was considered illicit BZD use. Further details on randomization, treatment and outcome were published previously (Haasen et al., 2007).

\section{Measures.}

For this study, BZD use was assessed according to weekly scheduled urine tests as well as self-reports (EuropASI). BZD prescription was extracted from medical prescription records. Addiction severity was assessed at baseline, 6 and 12 months using self-reported information according to the German version (Gsellhofer et al., 1999) of the EuropASI (Kokkevi and Stefanis, 1995) based on the fifth edition of the Addiction Severity Index, ASI (McLellan et al., 1992). Psychopathology was assessed with the Global Severity Index (GSI) of the Symptom Checklist-90-Revised (SCL-90-R, Derogatis, 1994), with a special focus in this study on the anxiety and phobic anxiety subscales assessed at baseline, 1, 3, 6 and 12 months of treatment. The same two primary outcome measures (POM) as in the overall study (Haasen et al., 2007) were used, namely improvement of health and reduction of illicit drug use. For the POM on health, study participants were considered responders if they showed at least 20\% improvement in the Opiate Treatment Index health scale (physical health) and/or at least $20 \%$ improvement in the GSI (mental health), without a deterioration of more than $20 \%$ in the other area of health. For the second POM of illicit drug use, participants were considered responders if they showed a reduction in the use of street heroin with at least 3 of 5 negative urines in the month prior to T12 and no increase in cocaine use (hair analysis).

Double-blind studies have been judged not to be feasible when comparing oral methadone with intravenous diamorphine due to methodological and ethical reasons (Bammer et al., 1999). To avoid treatment bias favoring the experimental treatment, a "worst case analysis" 
was performed: Drop-outs in the MMT group were considered responders, while those in the HAT group were considered non-responders.

\section{Study population.}

For the purposes of this study, patients were assigned to groups defined by their BZD use prior to admission and during treatment and by the pattern of BZD prescribing during care:

1) The full sample was divided into BZD users and non-users at baseline (baseline BZD use groups: BZD and NBZD). A patient was considered a BZD user at baseline if he/she reported at least one day of BZD use in the last month and/or had a BZD-positive urine at baseline. According to these criteria, a total of 736 patients were considered BZD users $(72.5 \%)$ and 279 were considered non-users $(27.5 \%)$.

2) As longitudinal data on weekly urines were only available over 12 months from patients who completed treatment, the analysis of benzodiazepine use during treatment focused on treatment completers. From the 1015 subjects in the full sample, 546 completed the treatment according to the study protocol [retention rate of $67.2 \%(n=346)$ for HAT patients and $40.0 \%$ $(n=200)$ for MMT patients]. Early termination of study treatment (non-completers) was either due to somatic complications, jail terms, violent behaviour, unexcused absence from treatment for more than two weeks or excused absence for more than three months.

Due to the long half-life of benzodiazepines and the resulting long time that they are detected in urine samples, a cut-off had to be chosen to differentiate between occasional and ongoing BZD use (ongoing BZD use groups). As the mean for BZD positive urines during treatment was $26.1 \%$ in the group of baseline BZD non-users (see figure 1 below), patients were considered ongoing users during treatment (OngBZD group) if they had at least $26.1 \%$ BZD positive urines during treatment. From the 546 completers, $366(67 \%)$ were considered 
ongoing users and $180(33 \%)$ had lower rates of positive urines and therefore were considered occasional users (OccBZD group).

3) Completers were split into three groups according to the pattern of benzodiazepine prescription (prescription groups). In the OngBZD group, a total of 265 (72.4\%, HAT: n=156, MMT; n=109) patients did not receive any prescription of benzodiazepines within the study treatment during the 12 months of treatment (no prescription group), 46 (12.6\%, HAT: $n=31$, MMT; $\mathrm{n}=15)$ were prescribed benzodiazepines for no more than 90 days $(25.4 \pm 24.6$, range $=1-90$ days; intermittent prescription group) and 55 (15.0\%, HAT: $n=31$, MMT; $n=24)$ for more than 90 days (285.5 \pm 90.0 , range $=108-365$ days; regular prescription group). Only 6 patients from the OccBZD users in the subsample of completers received a BZD prescription during treatment (HAT: 2 intermittently, MMT: 3 intermittently and one regularly).

\section{Data analysis.}

Baseline characteristics were compared between treatment and baseline BZD use groups using t-tests for continuous variables and Chi-square tests for nominal variables. Odds ratios were calculated to assess differences in treatment outcome and retention between baseline and ongoing BZD use. In order to analyze urine samples Friedman tests for nonparametric repeated measures comparisons were carried out. Pearson correlations were used to examine the association between positive urine tests and self-reported information on BZD use.

Regarding ongoing use of BZDs, odds ratios were also calculated to assess differences in treatment outcome between ongoing and occasional BZD users in the subsample of completers. Two factor RM ANOVAs were used to analyze changes over time in ASI Composite Scores (ASI CS) at three time points within treatment groups and ongoing BZD use groups. 
Concerning prescription of BZDs, also in the subsample of completers, binary logistic regressions were carried out in order to build an adjusted model to assess the effect of treatment, ongoing BZD use and type of prescription on the POMs health and drug use. As the type of BZD prescription has three levels, dummy variables were used in the analysis (Jaccard, 2001) taking the no prescription group as reference category. Changes in BZD positive urine tests and anxiety symptomatology (SCL-90-R anxiety and phobic anxiety subscales over 5 time points) were calculated using two factor RM ANOVAs within treatment and prescription groups.

The alpha level for all analyses was $\mathrm{p}<.05$. All the statistical analyses were conducted using SPSS 18.0 for Windows.

\section{Results}

\section{Baseline BZD use analysis}

\section{Sociodemographic characteristics.}

Table 1 shows sociodemographic data according to baseline BZD use groups and treatment groups. BZD users had $12.77 \pm 12.26$ days of use in the past 30 days prior to baseline (HAT group: $12.69 \pm 12.22$, MMT group: $12.86 \pm 12.33, \mathrm{t}=-.187$, n.s.). The proportion of BZD users was not found to be significantly different between treatment groups. Data on drug use, physical and mental health and ASI CS are provided in table 1. 
Table 1. Baseline characteristics of the full sample ( $\mathrm{n}=1015)$ according to treatment groups and baseline benzodiazepine use.

\begin{tabular}{|c|c|c|c|c|c|c|c|}
\hline & \multicolumn{3}{|l|}{ HAT } & \multicolumn{3}{|l|}{ MMT } & \multirow[b]{2}{*}{$\begin{array}{l}\text { Total significance between BZD and } \\
\text { NBZD }\end{array}$} \\
\hline & BZD & NBZD & Significance & BZD & NBZD & Significance & \\
\hline \multicolumn{8}{|l|}{ Sociodemographic characteristics } \\
\hline Female gender $(\mathrm{n}, \%)^{1}$ & $73,19.6$ & $30,21.0$ & $\chi^{2}=.119, p=.731$ & $66,18.1$ & $35,25.7$ & $\begin{array}{c}\chi^{2}=3.551, \\
p=.060\end{array}$ & $\chi^{2}=2.452, p=.117$ \\
\hline Age $(\text { mean } \pm S D)^{1}$ & $36.06 \pm 6.57$ & $36.52 \pm 6.94$ & $t=-.702, p=.483$ & $36.27 \pm 6.59$ & $37.33 \pm 7.28$ & $t=-2.293, p=.022$ & $t=-1.591, p=.112$ \\
\hline Education in years $(\text { mean } \pm S D)^{2}$ & $9.75 \pm 1.83$ & $10.01 \pm 1.65$ & $t=-1.453, p=.147$ & $9.71 \pm 1.86$ & $9.89 \pm 1.88$ & $t=-.985, p=.325$ & $t=-1.724, p=.085$ \\
\hline Employed $(\mathrm{n}, \%)^{4}$ & $44,11.9$ & $23,13.29$ & $\chi^{2}=1.781, p=.182$ & $41,11.3$ & $23,16.9$ & $\begin{aligned} & \chi^{2}=2.792 \\
& p<.095\end{aligned}$ & $\chi^{2}=4.504, p=.034$ \\
\hline Stable housing $(\mathrm{n}, \%)^{3}$ & $247,66.6$ & $107,75.4$ & $\begin{array}{c}\chi^{2}=3.697 \\
p=.054\end{array}$ & $253,69.5$ & $96,70.6$ & $\chi^{2}=.055, p=.814$ & $\chi^{2}=2.369, p=.124$ \\
\hline \multicolumn{8}{|l|}{ Information on heroin use $(\operatorname{mean} \pm \mathrm{SD})$} \\
\hline Age of beginning of use ${ }^{2}$ & $19.78 \pm 5.34$ & $20.59 \pm 5.38$ & $t=-1.524, p=.128$ & $20.00 \pm 5.18$ & $21.20 \pm 5.31$ & $t=-2.293, p=.022$ & $t=-2.681, p=.002$ \\
\hline Years of use ${ }^{2}$ & $13.65 \pm 6.18$ & $13.61 \pm 6.72$ & $t=.072, p=.943$ & $13.90 \pm 6.39$ & $12.83 \pm 6.14$ & $t=1.677, p=.094$ & $t=1.220, p=.223$ \\
\hline Days of use in the past 30 days $^{4}$ & $20.79 \pm 10.89$ & $22.85 \pm 10.42$ & $t=-1.949, p=.052$ & $20.59 \pm 10.82$ & $22.34 \pm 10.94$ & $t=-1.599, p=.110$ & $t=-2.516, p=.012$ \\
\hline \multicolumn{8}{|l|}{ Physical health } \\
\hline OTI health scale $(0-50 \text { pts, mean } \pm \text { SD })^{1}$ & $18.70 \pm 5.23$ & $18.89 \pm 5.16$ & $t=-.364, p=.716$ & $19.38 \pm 5.43$ & $18.49 \pm 5.22$ & $t=1.661, p=.097$ & $t=.930, p=.352$ \\
\hline HIV positive $(\mathrm{n}, \%)^{5}$ & $35,9.4$ & $9,6.5$ & $\begin{array}{c}\chi^{2}=1.123 \\
p=.289\end{array}$ & $39,10.8$ & $8,5.9$ & $\begin{array}{c}\chi^{2}=2.725 \\
p=.099\end{array}$ & $\chi^{2}=3.695, p=.055$ \\
\hline $\mathrm{HCV}$ positive $(\mathrm{n}, \%)^{5}$ & $300,81.1$ & $110,79.1$ & $\chi^{2}=.244, p=.621$ & $302,83.4$ & $105,77.8$ & $\begin{aligned} \chi^{2} & =2.115 \\
p & =.146\end{aligned}$ & $\chi^{2}=1.860, p=.173$ \\
\hline \multicolumn{8}{|l|}{ Mental health } \\
\hline At least one comorbid diagnostic; F2-F5 (n, \%) $)^{12}$ & $190,63.1$ & $63,52.5$ & $\chi^{2}=4.037$ & $93,64.6$ & $33,54.1$ & $\chi^{2}=1.989$ & $\chi^{2}=6.003, p=.014$ \\
\hline
\end{tabular}




\begin{tabular}{|c|c|c|c|c|c|c|c|}
\hline & & & $p=.045$ & & & $p=.158$ & \\
\hline SCL-90-R GSI (T value) $(\text { mean } \pm \text { SD })^{1}$ & $69.86 \pm 10.42$ & $66.41 \pm 11.86$ & $t=3.051, p=.003$ & $70.42 \pm 9.64$ & $67.78 \pm 10.13$ & $t=2.691, p=.007$ & $t=4.034, p<.0001$ \\
\hline SCL-90-R Anxiety value $\left(\right.$ mean \pm SD) ${ }^{1}$ & $1.08 \pm 0.74$ & $.93 \pm .76$ & $t=2.061, p=.040$ & $1.13 \pm .79$ & $.95 \pm .77$ & $t=2.178, p=.030$ & $t=3.005, p=.003$ \\
\hline SCL-90-R Phobic anxiety value $\left(\right.$ mean \pm SD) ${ }^{1}$ & $.68 \pm .68$ & $.62 \pm .68$ & $t=.954, p=.340$ & $.73 \pm .70$ & $.58 \pm .65$ & $t=2.166, p=.031$ & $t=2.207, p=.028$ \\
\hline \multicolumn{8}{|c|}{$\begin{array}{l}\text { Addiction Severity Index Composite Scores at baseline } \\
(\text { mean } \pm \text { SD) }\end{array}$} \\
\hline Physical state of health ${ }^{5}$ & $.44 \pm .34$ & $0.37 \pm 0.31$ & $t=1.999, p=.046$ & $0.43 \pm 0.35$ & $0.38 \pm 0.35$ & $t=1.690, p=.092$ & $t=2.606, p=.009$ \\
\hline Economic situation $^{6}$ & $.92 \pm .22$ & $.90 \pm .27$ & $t=1.058, p=.291$ & $.95 \pm .17$ & $.87 \pm .29$ & $t=3.855, p=.003$ & $t=3.325, p<.001$ \\
\hline Satisfaction from work ${ }^{13}$ & $.39 \pm .33$ & $.39 \pm .36$ & $t=-.030, p=.976$ & $.35 \pm .34$ & $.35 \pm .33$ & $t=.037, p=.970$ & $t=.010, p=.992$ \\
\hline Drug use ${ }^{8}$ & $.39 \pm .10$ & $.35 \pm .09$ & $t=4.666, p<.0001$ & $.40 \pm .10$ & $.35 \pm .09$ & $t=4.863, p<.0001$ & $t=7.113, p<.0001$ \\
\hline Alcohol use $^{9}$ & $.12 \pm .18$ & $.12 \pm .20$ & $t=-.128, p=.898$ & $.13 \pm .20$ & $.09 \pm .17$ & $t=2.028, p=.044$ & $t=1.258, p=.209$ \\
\hline Legal status and problems ${ }^{11}$ & $.43 \pm .27$ & $.37 \pm .27$ & $t=2.160, p=.031$ & $.42 \pm .27$ & $.34 \pm .26$ & $t=2.917, p=.004$ & $t=3.573 . p<.0001$ \\
\hline Family relationships ${ }^{7}$ & $.29 \pm .21$ & $.24 \pm .20$ & $t=2.385, p=.017$ & $.28 \pm .20$ & $.24 \pm .20$ & $t=1.720, p=.086$ & $t=2.918 \cdot p=.004$ \\
\hline Social environment relationships ${ }^{10}$ & $.24 \pm .20$ & $.24 \pm .21$ & $t=1.441, p=.150$ & $.29 \pm .22$ & $.26 \pm .22$ & $t=1.432, p=.153$ & $t=2.027 \cdot p=.043$ \\
\hline Mental status ${ }^{8}$ & $0.26 \pm 0.21$ & $0.18 \pm 0.19$ & $t=3.868, p<.0001$ & $0.26 \pm 0.23$ & $0.20 \pm 0.20$ & $t=2.842, p<.005$ & $t=4.735 . p<.0001$ \\
\hline
\end{tabular}

Sample size: 1 n=1015, 2 n=1014, 3 n=1013, 4 n=1011, 5 n=1006, 6 n=988, 7 n= 985, 8 n=968, 9 n= 965, 10 n=953, 11 n=951, 12 n=626, $13 n=436$

HAT: Heroin Assisted Treatment group (total n=515); MMT: Methadone Maintenance Treatment group (total n=500).

BZD: BZD use at baseline; NBZD: No BZD use at baseline (criteria: positive urine or at least one day of use in the last 30 days at baseline examination). 
BZD users at baseline were found to be less often employed, initiated heroin use at an earlier age, had less days of heroin use in the past month but more days of cannabis use, were more likely to have a comorbid diagnosis, and have higher SCL-90-R T anxiety and phobic anxiety subscale scores. Regarding ASI CS, they had higher scores (indicating higher severity) for physical state of health, economic situation, drug use, legal problems, family, social relations and mental status areas. Although not statistically significant, BZD users were more likely to be HIV positive.

\section{Relation of baseline BZD use with treatment retention and outcome.}

Table 2 shows treatment retention and POMs by treatment group and BZD use at baseline. A statistically significant higher retention rate can be observed in those patients who did not use benzodiazepines at baseline. This difference is significant only in the HAT treatment group, not in the MMT group. No significant differences were detected in outcome measures. 
Table 2: Treatment retention and primary outcome measure (POM) response according to treatment groups and baseline benzodiazepine use (n,

$\%)$ in the full sample*.

\begin{tabular}{|c|c|c|c|c|c|c|c|c|c|}
\hline & \multicolumn{3}{|l|}{ HAT } & \multicolumn{3}{|l|}{ MMT } & \multicolumn{3}{|l|}{ Total } \\
\hline & BZD & NBZD & Significance & BZD & NBZD & Significance & BZD & NBZD & $\begin{array}{c}\text { Total significance } \\
\text { between BZD and } \\
\text { NBZD }\end{array}$ \\
\hline $\begin{array}{l}12 \text { months } \\
\text { retention }\end{array}$ & $\begin{array}{l}240 \\
64.5\end{array}$ & $\begin{array}{l}106 \\
74.1\end{array}$ & $\begin{array}{c}\mathrm{OR}=.635,95 \% \\
\mathrm{CI}=.413-976 ; \\
\mathrm{p}=.038\end{array}$ & $\begin{array}{l}140, \\
38.5\end{array}$ & $\begin{array}{l}60 \\
44.1\end{array}$ & $\begin{array}{l}\mathrm{OR}=.792,95 \% \mathrm{CI}= \\
.531-1.180 ; \mathrm{p}=.251\end{array}$ & $\begin{array}{c}380 \\
51.63\end{array}$ & $\begin{array}{c}166 \\
59.50\end{array}$ & $\begin{array}{c}\mathrm{OR}=.727,95 \% \mathrm{CI}= \\
.550-.961 ; \mathrm{p}=.025\end{array}$ \\
\hline $\begin{array}{l}\text { POM health } \\
\text { improvement }\end{array}$ & $\begin{array}{l}293 \\
78.8\end{array}$ & $\begin{array}{l}119, \\
83.2\end{array}$ & $\begin{array}{c}\mathrm{OR}=.748,95 \% \\
\mathrm{CI}=.452-1.238 ; \\
\mathrm{p}=.258\end{array}$ & $\begin{array}{l}269 \\
73.9\end{array}$ & $\begin{array}{l}101 \\
74.3\end{array}$ & $\begin{array}{l}\mathrm{OR}=.981,95 \% \mathrm{CI}= \\
.626-1.539 ; p=.934\end{array}$ & $\begin{array}{c}562 \\
76.36\end{array}$ & $\begin{array}{c}220 \\
78.85\end{array}$ & $\begin{array}{l}\mathrm{OR}=.866,95 \% \mathrm{CI}= \\
.620-1.210 ; p=.399\end{array}$ \\
\hline
\end{tabular}

*These variables were measured for all the participants and therefore there are no missing values $(n=1015$, HAT $n=515$, MMT $n=500)$.

BZD: BZD use at baseline (report of at least one day of BZD use in the last month and/or positive urine analysis at baseline), NBZD: No BZD use at baseline, POM: Primary Outcome Measure 


\section{BZD use during treatment.}

Figure 1 shows weekly percentage of all treated patients with BZD positive tests in urine samples during the 12-month treatment period according to treatment and baseline BZD use groups, with a greater decrease in BZD positive tests in the HAT treatment group. The mean for BZD positive tests in urine samples was $52.3 \%$ for HAT patients and $60.3 \%$ for MMT patients. A Friedman test carried out with the full sample showed a significantly greater reduction in BZD positive urines for HAT patients compared to MMT patients (Friedman's $\left.\chi^{2}=50.074, p<.0001\right)$. Baseline BZD users had an average of $67.2 \%$ positive tests and baseline non-users of $26.1 \%$ in the 12 -month treatment period. Among baseline BZD users, HAT patients showed a greater but not significant reduction in BZD positive tests in urine samples (mean of positives; HAT: 64.3\%, MMT: 65.9\%), while among baseline non-users the percentage BZD positive urines was less in HAT than MMT patients (mean of positives; HAT: $21.8 \%$, MMT: $28.1 \%$ ). The proportion of BZD positive tests in urine samples showed positive correlations with ASI information on BZD use in the last 30 days at both baseline (full sample $\mathrm{r}=.464, \mathrm{p}<.0001$, completers $\mathrm{r}=.499, \mathrm{p}<.0001$ ) and at 12 months (full sample $\mathrm{r}=.499, \mathrm{p}<.0001$, completers $\mathrm{r}=.492, \mathrm{p}<.0001)$.

\section{Ongoing BZD use analysis}

Using the cut-off of $26.1 \%$ of BZD positive urines to differentiate between occasional and ongoing users, correspondence of BZD baseline and ongoing use was significantly high $\left(\chi^{2}=107.033, \mathrm{p}<.0001\right)$, showing that $80.8 \%$ of the baseline users remained ongoing users while only $35.5 \%$ of the baseline non users became ongoing users. 
Figure 1. Percentage of positive benzodiazepine urines by treatment group (left) and by baseline BZD use (right) for the full sample*.

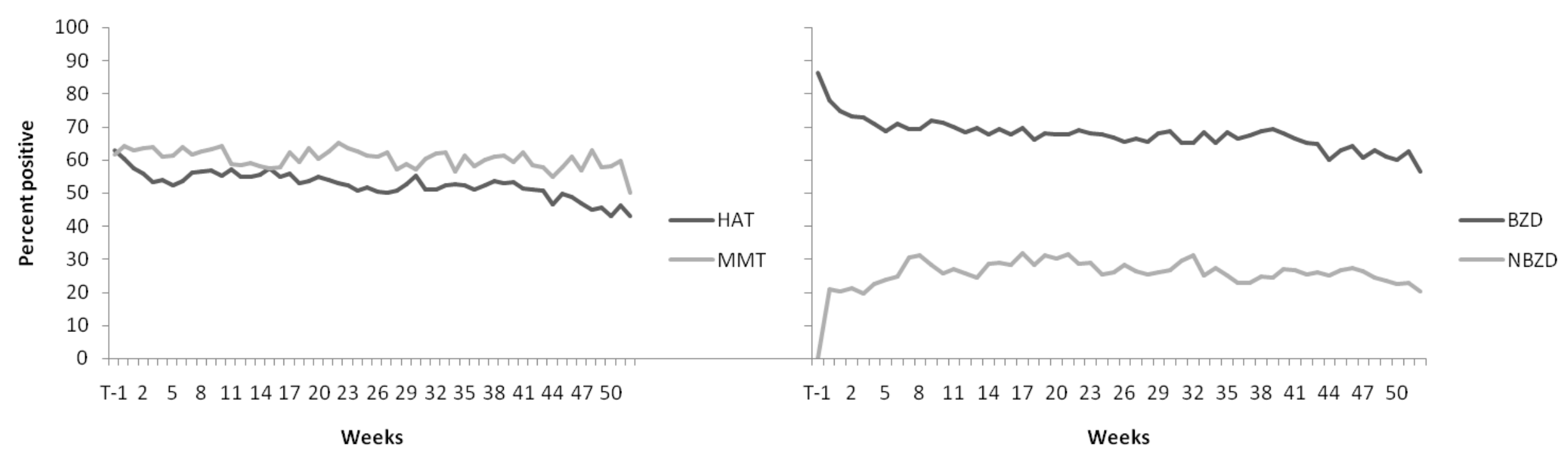

* Urine tests were scheduled weekly for all the patients in treatment $(\mathrm{n}=1015)$. At baseline 984 urines were tested. During treatment, missing urine samples ranged from 209 to 519. 
Table 3: Primary outcome measure (POM) response according to treatment groups and ongoing benzodiazepine use (n, \%) in the sample of completers*.

\begin{tabular}{|c|c|c|c|c|c|c|c|c|c|}
\hline & HAT & & & MMT & & & Total & & \\
\hline & OngBZD & OccBZD & Significance & OngBZD & OccBZD & Significance & OngBZD & OccBZD & $\begin{array}{c}\text { Total significance } \\
\text { between OngBZD and } \\
\text { OccBZD }\end{array}$ \\
\hline $\begin{array}{l}\text { POM reduction of } \\
\text { illicit drug use }\end{array}$ & $153,70.2$ & $\begin{array}{l}100 \\
78.1\end{array}$ & $\begin{array}{l}O O R=.659,95 \% C I= \\
.396-1.097 ; p=.108\end{array}$ & $\begin{array}{c}74 \\
50.1\end{array}$ & $29,55.8$ & $\begin{array}{l}O R=.793,95 \% C I= \\
.420-1.497 ; p=.474\end{array}$ & $227,62.0$ & $\begin{array}{l}129 \\
71.7\end{array}$ & $\begin{aligned} O R= & .646,95 \% C I=.439 \\
& -.516 ; p=.026\end{aligned}$ \\
\hline $\begin{array}{l}\text { POM health } \\
\text { improvement }\end{array}$ & $183,83.9$ & $\begin{array}{l}118 \\
92.2\end{array}$ & $\begin{array}{l}O R=.443,95 \% C I= \\
.211-.929 ; p=.028\end{array}$ & $106,71.6$ & $48,92.3$ & $\begin{array}{l}O R=.210,95 \% C I= \\
.071-.620 ; p=.002\end{array}$ & $289,79.0$ & $\begin{array}{l}166 \\
92.2\end{array}$ & $\begin{aligned} O R= & .317,95 \% C I=.174 \\
& -.577 ; p<.0001\end{aligned}$ \\
\hline
\end{tabular}

*This table was calculated using data from the participants who completed the treatment ( $\mathrm{n}=546$, HAT $n=346$, MMT $n=200)$.

OngBZD: ongoing BZD use; OccBZD: Occasional BZD use (less than 26.1\% positive urines during treatment). 


\section{Ongoing BZD use relation with treatment outcomes.}

Table 3 shows POMs by treatment and ongoing benzodiazepine use in the subsample of completers $(\mathrm{n}=546)$. Ongoing BZD use was found to have a negative association with health outcome in both treatment groups but, when analyzing drug use outcome, differences were only statistically significant when both treatment groups were combined.

Results of the repeated measures analysis of variance of ASI composite scores (CS) showed that ongoing BZD use was statistically associated with significantly poorer results in CS for satisfaction from work (Pillai's Trace=.072, F=3.320, $\mathrm{p}<.05$ ), alcohol use (Pillai's Trace $=.025, \mathrm{~F}=6.004, \mathrm{p}<.005$ ) and social relationships (Pillai's Trace $=.013, \mathrm{~F}=2.975, \mathrm{p}<.05$ ), while HAT patients with ongoing BZD use performed better on CS for alcohol use (Pillai's Trace $=.044, \mathrm{~F}=11.008, \mathrm{p}<.0001$ ), drug use (Pillai's Trace=.186, $\mathrm{F}=51.524, \mathrm{p}<.0001$ ), and legal status and problems (Pillai's Trace $=.026, \mathrm{~F}=6.275, \mathrm{p}=.002$ ) compared to MMT patients with ongoing BZD use.

\section{BZD prescription analysis}

\section{Type of benzodiazepine prescribed.}

Among completers, patients were prescribed diazepam $(n=75,69.5 \%)$, clonazepam $(n=15,13.9 \%)$, flunitrazepam $(n=7,6.5 \%)$, oxazepam $(n=3,2.8 \%)$, lorazepam $(n=3,2.8 \%)$, clorazepate $(n=2,1.9 \%)$, temazepam, nitrazepam and lormetazepam $(n=1$ each, $0.9 \%)$. During treatment, $21(19.4 \%)$ of these patients had a prescription change to another type of benzodiazepine.

\section{BZD prescription and outcome measures.}

The results of the adjusted model for the sample of treatment completers receiving prescribed benzodiazepines, with ongoing BZD use and treatment groups as independent variables, showed that only treatment group was a reliable predictor of the POM on drug use with better results for the HAT group $(\mathrm{OR}=2.513,95 \% \mathrm{CI}=1.738-3.634)$. Belonging to the 
HAT treatment group and having an occasional BZD use predicted better results for the POM on health (Treatment: $\mathrm{OR}=1.802,95 \% \mathrm{CI}=1.113-2.866$; Ongoing BZD use: $\mathrm{OR}=.331$, 95\%CI=.178-.615). Regarding prescription patterns, no significant differences were found when comparing regular or irregular prescription with no prescription at all. For the POM on health, the intermittent prescription group $(\mathrm{OR}=.438,95 \% \mathrm{CI}=.166-1.157)$ as well as the regular prescription group $(\mathrm{OR}=1.326,95 \% \mathrm{CI}=.683-2.575)$ did not differ significantly from the no prescription group. For the POM on drug use, the intermittent prescription group $(\mathrm{OR}=1.357,95 \% \mathrm{CI}=.745-2.538)$ as well as the regular prescription group $(\mathrm{OR}=.812$, 95\% CI=.438-1.507) did not differ significantly from the no prescription group.

\section{Course of anxiety symptomatology according to pattern of BZD prescription.}

SCL-90-R scores for anxiety and phobic anxiety by treatment group in the completers sample can be seen in figure 2. Both scores showed a significant time effect (anxiety: Pillais trace=.170, F=25.949, p>.0001; phobic anxiety: Pillais Trace=.129, F=18.791, p>.0001). Despite a greater decrease in anxiety and phobic anxiety scores in the HAT group, the effects were not statistically significant for treatment groups (anxiety: Pillais Trace=.010, F=1.317, $\mathrm{p}=.262$; phobic anxiety: Pillais Trace $=.033, \mathrm{~F}=.164, \mathrm{p}=.686$ ). Nevertheless a significant effect of BZD prescription was detected in phobic anxiety (Pillais Trace=.045, $\mathrm{F}=2.928, \mathrm{p}<.005$ ), reflecting a higher decrease of phobic anxiety in the regular prescription group. 
Figure 2. Anxiety (left) and phobic anxiety (right) GSL SCL-90-R scores by treatment group in the subsample of completers*.

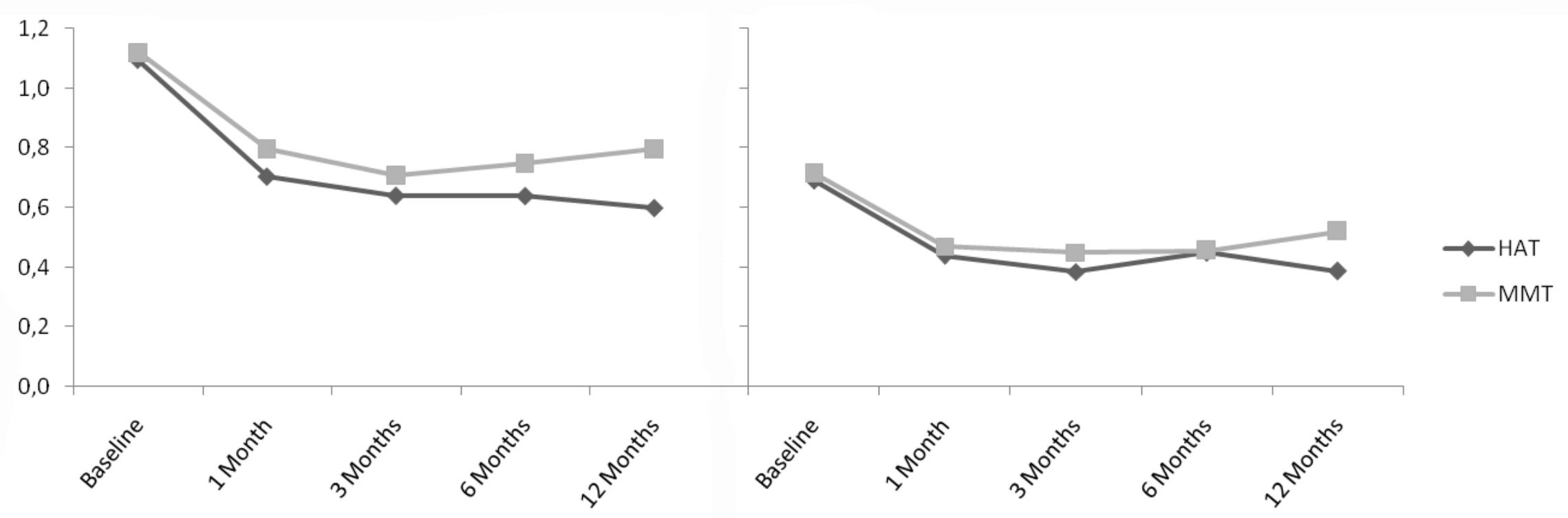

* Scores calculated in the subsample of completers $(n=546)$ in those patients whose anxiety levels were registered in all the 5 time points $(\mathrm{N}=516$, HAT $\mathrm{n}=330$, MMT $\mathrm{n}=186)$. 


\section{Discussion}

Benzodiazepine use at treatment entry and during opioid maintenance treatment is a marker for greater complexity of patient need and poorer treatment outcomes in previous studies. This study confirms several findings of previous studies including: BZD use at treatment entry is associated with more severe problems related to drug use, physical health and psychosocial function, and an earlier age of initiation of heroin use; BZD use at baseline is highly correlated with ongoing BZD use during treatment; ongoing BZD use during methadone maintenance treatment is associated with poorer treatment outcome but does not lead to decreased treatment retention in MMT (Brands et al., 2008).

This study extends the findings from previous studies by also evaluating the impact of BZD use on outcomes from Heroin-Assisted Treatment (HAT). Using an intent-to-treat analysis and predefined primary outcome measures, the present study showed no negative impact of BZD use on treatment outcomes from HAT. This may be related to the generally negative outcomes for those who leave treatment regardless of BZD use. Baseline BZD use also led to poorer treatment retention in HAT, distinct from the absence of such an effect on MMT retention. BZD use has been linked to increased rates of non-fatal overdose in heroin users (Kerr et al., 2005) and it is possible that the negative impact on HAT retention arises from increased sedation among BZD users limiting the ability to prescribe an effective dose of diamorphine.

Focussing only on treatment completers, ongoing BZD use during care is associated with poorer outcomes in both MMT and HAT for health and poorer outcomes for drug use when both opioid treatment groups are combined. BZD users however had a greater reduction in BZD use and better outcomes for drug use, alcohol use and legal problems when treated with HAT than with MMT. This suggests that HAT may be a preferred treatment option for long-term opioid dependent patients with benzodiazepine dependence despite the reduced treatment retention discussed above. 
In this study, benzodiazepine users at baseline had a higher level of mental distress and greater levels of anxiety and phobic anxiety. This suggests that the illicit use of benzodiazepines in this patient population may arise from underlying mental health issues. Indeed, those patients with ongoing BZD use who were prescribed benzodiazepines during the study reported a greater reduction in phobic anxiety symptoms. In general, prescription of benzodiazepines during maintenance treatment has been cautiously suggested for some patients. Only one in four patients with ongoing BZD use received a benzodiazepine prescription during the trial, about half of them received a prescription not just intermittently, but on a regular basis, demonstrating how cautiously benzodiazepines were prescribed despite the high level of mental health problems. This suggests that illicit benzodiazepine use remains an important factor to consider. However, the results do not show significant outcome differences between the two prescription groups and the group with ongoing illicit BZD use. Considering the fact that illicit BZD use is also associated with illicit polydrug use as well as criminal behavior, loosening the restrictive criteria for prescribing BZD (if indicated) in this population may be recommended in order to a) avoid illicit BZD use, b) have some input in the type of medication (short or long term, side effects) and c) have better dosage control. Future randomized studies evaluating the impact of prescribing benzodiazepines to opioid maintenance treatment patients with ongoing BZD use may be warranted to clarify the clinical situations in which this is in the best interests of patients.

With respect to the choice of opioid maintenance treatment in the face of BZD use, HAT seems to be associated with a lower percentage of positive BZD urine tests during the 12 months, and ongoing BZD users in HAT showed better outcome measures than those in MMT in some of the composite scores for addiction severity. Illicit benzodiazepine use should be seen in a broader context of polydrug use, where additional sedation of benzodiazepines may be wanted to balance out other effects of illicit drugs such as cocaine and street heroin. Therefore, the overall better effect of HAT in reducing illicit drug use 
(Haasen et al., 2007; March et al., 2006; van den Brink et al., 2003) may be associated with the reduction of benzodiazepine use. The stronger association of HAT and BZD decrease may also be explained in part by neurobiological aspects, which could also explain why BZD use is lower among heroin dependents not in maintenance treatment (Backmund et al., 2005). Benzodiazepines, especially flunitrazepam, have been found to boost the subjective effects of methadone (Busto et al., 1996), and diazepam has been found to increase the effect of methadone by some undetermined mechanism (Eap et al., 2002). BZD effects have yet to be shown in an interaction with diamorphine (heroin) and may well differ considering the different pharmacokinetic profiles of diamorphine and methadone. The greater dopamine release of diamorphine in the mesolimbic dopamine system (Devine et al., 1993) may also lead to less concomitant BZD use. It has been shown that chronic treatment with opiates alters BZD receptor binding and $\mathrm{GABA}_{\mathrm{A}}$ receptor function (Lopez et al., 1990; Sivam and Ho, 1982), and it is possible that various opiate ligands exert differential effects on the GABA receptor. These neurobiological aspects will have to be examined in future experimental studies.

There are limitations of this study that need to be considered. The study was not set out to analyze the effect of maintenance treatment on benzodiazepine use, so no causality can be attributed and the associations found need to be confirmed in future trials. The patient groups are not randomized according to BZD use, and baseline differences - such as more mental distress among BZD users - are not controlled for. Furthermore, there is no data on prescription of BZD by other doctors, as well as no possibility to distinguish between prescribed and non-prescribed BZD at baseline. Finally, the differentiation between occasional and ongoing BZD use needs to be validated in future studies, as the cut-off used in this study may not be sufficiently reliable.

The results confirm the cautious attitude towards prescribing benzodiazepines of physicians in maintenance treatment, but also suggest that benzodiazepine prescription may 
not have to be considered so restrictively in difficult-to-treat opioid dependent patients. These findings may need to be reflected in treatment guidelines. Future research will have to determine whether the correlation with negative treatment outcome is due to BZD use, or whether improvement during treatment leads to lower BZD demand.

\section{References}

Backmund, M., Meyer, K., Henkel, C., Soyka, M., Reimer, J., Schutz, C.G., 2005. Coconsumption of benzodiazepines in heroin users, methadone-substituted and codeinesubstituted patients. J Addict Dis 24, 17-29.

Bammer, G., Dobler-Mikola, A., Fleming, P.M., Strang, J., Uchtenhagen, A., 1999. Drug Abuse: The Heroin Prescribing Debate: Integrating Science and Politics. Science 284, $1277-1278$.

Batki, S.L., Kauffman, J.F., Marion, I., Parrino, M.W., Woody, G.E., 2005. MedicationAssisted Treatment For Opioid Addiction in Opioid Treatment Programs. U.S. Department of Health and Human Services, Substance Abuse and Mental Health Services Administration, Center for Substance Abuse Treatment, Rockville. p. 183.

Blanken, P., Hendriks, V.M., Koeter, M.W., van Ree, J.M., van den Brink, W., 2005. Matching of treatment-resistant heroin-dependent patients to medical prescription of heroin or oral methadone treatment: results from two randomized controlled trials. Addiction 100, 89-95.

Bleich, A., Gelkopf, M., Schmidt, V., Hayward, R., Bodner, G., Adelson, M., 1999. Correlates of benzodiazepine abuse in methadone maintenance treatment. A 1 year prospective study in an Israeli clinic. Addiction 94, 1533-1540.

Bramness, J.G., Kornør, H., 2007. Benzodiazepine prescription for patients in opioid maintenance treatment in Norway. Drug Alcohol Depend 90, 203-209.

Brands, B., Blake, J., Marsh, D.C., Sproule, B., Jeyapalan, R., Li, S., 2008. The Impact of 
Benzodiazepine Use on Methadone Maintenance Treatment Outcomes. J Addict Dis $27,37-48$.

Brunette, M.F., Noordsy, D.L., Xie, H., Drake, R.E., 2003. Benzodiazepine Use and Abuse Among Patients With Severe Mental Illness and Co-occurring Substance Use Disorders. Psychiatr Serv 54, 1395-1401.

Busto, U.E., Romach, M.K., Sellers, E.M., 1996. Multiple Drug Use and Psychiatric Comorbidity in Patients Admitted to the Hospital With Severe Benzodiazepine Dependence. . J Clin Psychopharmacol 16, 51-57.

Darke, S., 1994. Benzodiazepine use among injecting drug users: problems and implications. Addiction 89, 379-382.

Darke, S., Swift, W., Hall, W., Ross, M., 1993. Drug use, HIV risk-taking and psychosocial correlates of benzodiazepine use among methadone maintenance clients. Drug Alcohol Depend 34, 67-70.

Derogatis, L.R., 1994. SCL-90-R: Administration, scoring and procedures manual (3rd edition), Baltimore.

Devine, D.P., Leone, P., Pocock, D., Wise, R.A., 1993. Differential involvement of ventral tegmental mu, delta and kappa opioid receptors in modulation of basal mesolimbic dopamine release: in vivo microdialysis studies. J Pharmacol Exp Ther 266, 12361246.

Eap, C.B., Buclin, T., Baumann, P., 2002. Interindividual Variability of the Clinical Pharmacokinetics of Methadone: Implications for the Treatment of Opioid Dependence. Clin Pharmacokinet 41, 1153-1193.

Gsellhofer, B., Küfner, H., Vogt, M., Weiler, D., 1999. Nach der 5 Auflage der amerikanischen Version von McLellan und der Europäischen Version des ASI Schneider Verlag Hohengehren, Baltmannsweiler.

Haasen, C., Verthein, U., Degkwitz, P., Berger, J., Krausz, M., Naber, D., 2007. Heroin- 
assisted treatment for opioid dependence: Randomised controlled trial. Br J Psychiatry $191,55-62$.

Jaccard, J., 2001. Interaction effects in logistic regression, Thousand Oaks, CA.

Johnson, B., Longo, L.P., 1998. Considerations in the physician's decision to prescribe benzodiazepines to patients with addiction. Psychiatr Ann 28, 160-165.

Kerr, T., Marsh, D., Li, K., Montaner, J., Wood, E., 2005. Factors associated with methadone maintenance therapy use among a cohort of polysubstance using injection drug users in Vancouver. Drug Alcohol Depend 80, 329-335.

Kokkevi, A., Stefanis, C., 1995. Drug abuse and psychiatric comorbidity. Compr Psychiatry $36,329-337$.

Lopez, F., Miller, L., Thompson, M., Schatzki, A., Chesley, S., Greenblatt, D., Shader, R., 1990. Chronic morphine administration augments benzodiazepine binding and GABAA receptor function. Psychopharmacology (Berl) 101, 545-549.

March, J.C., Oviedo-Joekes, E., Perea-Milla, E., Carrasco, F., 2006. Controlled trial of prescribed heroin in the treatment of opioid addiction. J Subst Abuse Treat 31, 203211.

McLellan, A.T., Kushner, H., Metzger, D., Peters, R., Smith, I., Grissom, G., Pettinati, H., Argeriou, M., 1992. The fifth edition of the addiction severity index. J Subst Abuse Treat 9, 199-213.

Meiler, A., Mino, A., Chatton, A., Broers, B., 2005. Benzodiazepine use in a methadone maintenance programme : patient characteristics and the physician's dilemma. Schweiz Arch Neurol Psychiatr 156, 310-317.

Oviedo-Joekes, E., Brissette, S., Marsh, D.C., Lauzon, P., Guh, D., Anis, A., Schechter, M.T., 2009. Diacetylmorphine versus Methadone for the Treatment of Opioid Addiction. N Engl J Med 361, 777-786.

Perneger, T.V., Giner, F., del Rio, M., Mino, A., 1998. Randomised trial of heroin 
maintenance programme for addicts who fail in conventional drug treatments. BMJ 317, 13-18.

Rehm, J., Gschwend, P., Steffen, T., Gutzwiller, F., Dobler-Mikola, A., Uchtenhagen, A., 2001. Feasibility, safety, and efficacy of injectable heroin prescription for refractory opioid addicts: a follow-up study. The Lancet 358, 1417-1420.

Seivewright, N., Iqbal, M.Z., 2002. Prescribing to drug misusers in practice;often effective, but rarely straightforward. Addict Biol 7, 269-277.

Sivam, S.P., Ho, I.K., 1982. Influence of morphine dependence on GABA-stimulated benzodiazepine binding to mouse brain synaptic membranes. Eur J Pharmacol 79, 335-336.

Stitzer, M.L., Bigelow, G.E., Liebson, I.A., Hawthorne, J.W., 1982. Contingent reinforcement for benzodiazepine-free urines: evaluation of a drug abuse treatment intervention. JApplBehavAnal 15, 493-503.

van den Brink, W., Hendriks, V.M., Blanken, P., Koeter, M.W.J., van Zwieten, B.J., van Ree, J.M., 2003. Medical prescription of heroin to treatment resistant heroin addicts: two randomised controlled trials. BMJ 327, 310-315.

Verthein, U., Bonorden-Kleij, K., Degkwitz, P., Dilg, C., hler, W.K., Passie, T., Soyka, M., Tanger, S., Vogel, M., Haasen, C., 2008. Long-term effects of heroin-assisted treatment in Germany. Addiction 103, 960-966.

Weizman, T., Gelkopf, M., Melamed, Y., Adelson, M., Bleich, A., 2003. Treatment of benzodiazepine dependence in methadone maintenance treatment patients: a comparison of two therapeutic modalities and the role of psychiatric comorbidity. Aust N Z J Psychiatry 37, 458-463. 